\title{
Effects of Lithium Salt Concentration in Ionic Liquid Electrolytes on Battery Performance of $\mathrm{LiNi}_{0.5} \mathrm{Mn}_{0.3} \mathrm{CO}_{0.2} \mathrm{O}_{2} / \mathrm{Graphite}$ Cells
}

\author{
Takuya TAKAHASHI, ${ }^{a, b, \S}$ Masashi ISHIKAWA, ${ }^{a, c, *, \S \S ~(i) ~ Y o s u k e ~ U G A T A, ~}{ }^{b, \S \S \S}$



\author{
a iElectrolyte Co., Ltd., Center for Innovation \& Creativity of Kansai University, 3-3-35 Yamate-cho, Suita, Osaka 564-8680, Japan \\ ${ }^{b}$ Department of Chemistry and Life Science, Yokohama National University, 79-5 Tokiwadai, Hodogaya-ku, Yokohama 240-8501, Japan \\ ' Department of Chemistry and Materials Engineering, Faculty of Chemistry, Materials and Bioengineering, Kansai University, \\ 3-3-35 Yamate-cho, Suita, Osaka 564-8680, Japan \\ ${ }^{d}$ Advanced Chemical Energy Research Center (ACERC), Institute of Advanced Sciences, Yokohama National University, \\ 79-5 Tokiwadai, Hodogaya-ku, Yokohama 240-8501, Japan
}

*Corresponding author: masaishi@kansai-u.ac.jp

\section{ABSTRACT}

Ionic liquids (ILS) possess low volatility and low flammability and are promising electrolytes for thermally stable Li-ion batteries (LIBs). Among ILs, bis(fluorosulfonyl)imide ( $\mathrm{FSI}^{-}$) anion-based ILs have low viscosity and high ionic conductivity and FSI-based electrolytes are useful for achieving a high power density LIB. In this study, we investigated the effects of LiFSI concentration in IL electrolytes on the performance of LIBs. We prepared electrolytes composed of 1-ethyl-3-methyl imidazolium bis(fluorosulfonyl)imide (EMImFSI) and LiFSI. The ionic conductivity of the electrolyte decreased with increasing LiFSI concentration due to an increase in viscosity; however, the Li ${ }^{+}$ transference number increased with increasing LiFSI concentration. The IL electrolyte was tested in a $\mathrm{LiNi}_{0.5} \mathrm{Mn}_{0.3} \mathrm{Co}_{0.2} \mathrm{O}_{2} / \mathrm{graphite}$ pouch cell. The discharge rate capability of the cell was improved by increasing the LiFSI concentration. The higher LiFSI concentration was effective in suppressing the depletion of $\mathrm{Li}^{+}$in the vicinity of the cathode during the high current discharge. Furthermore, we demonstrated that cells with IL electrolytes can be stably operated over 500 charge-discharge cycles at $25^{\circ} \mathrm{C}$ and $60^{\circ} \mathrm{C}$.

(C) The Author(s) 2021. Published by ECSJ. This is an open access article distributed under the terms of the Creative Commons Attribution 4.0 License (CC BY, http://creativecommons.org/licenses/by/4.0/), which permits unrestricted reuse of the work in any medium provided the original work is properly cited. [DOI: 10.5796/electrochemistry.21-00075].

Keywords : Li-Ion Batteries, lonic Liquids, Lithium Bis(fluorosulfonyl)imide, Diffusion

\section{Introduction}

Lithium-ion batteries (LIBs) are widely used in portable devices, stationary energy storage devices, and electric vehicles. In addition to electrode materials, electrolytes significantly affect the performance of LIBs. Conventionally, non-aqueous liquid electrolytes are commonly used in practical LIBs. It is well known that small amounts of additives dissolved in electrolytes can improve the performance of LIBs. ${ }^{1-3}$ In addition, novel electrolytes - such as highly concentrated electrolytes ${ }^{4,5}$ and ionic liquid (IL) electrolytes ${ }^{6}$ - have also been investigated by many research groups. ILs possess low volatility and low flammability, which can improve the safety and reliability of LIBs. There are many ILs consisting of various cations and anions and their physicochemical properties change depending on the structure of the ions. Among them, bis(fluorosulfonyl)imide (FSI) anion-based ILs have attracted much attention as electrolytes for LIBs owing to their superior properties, such as low viscosity, high ionic conductivity, and wide electrochemical window. Ishikawa et al. first reported that reversible $\mathrm{Li}^{+}$intercalation into graphite electrodes is possible in an IL composed of 1-ethyl-3-methyl imidazolium bis(fluorosulfonyl)imide (EMImFSI) and lithium bis(trifluoromethanesulfonyl)imide (LiTFSI). ${ }^{7}$ They also demonstrated that FSI-based ILs are applicable

\footnotetext{
${ }^{\S}$ ECSJ Active Member

$\S \S$ ECSJ Fellow

$\$ \$ \&$ ECSJ Student Member

M. Ishikawa (D) orcid.org/0000-0003-4812-7505

K. Dokko (D) orcid.org/0000-0002-9622-4345

M. Watanabe (D) orcid.org/0000-0003-4092-6150
}

to $\mathrm{LiNi}_{1-x-y} \mathrm{Mn}_{x} \mathrm{Co}_{y} \mathrm{O}_{2} / \mathrm{Li}^{8}{ }^{8}$ silicon-nickel-carbon/Li, ${ }^{9}$ and sulfur/ lithiated silicon ${ }^{10}$ cells. The performance of the cells with FSI-based ILs was comparable to that of cells with conventional carbonatebased electrolytes, containing $\mathrm{LiPF}_{6}$. Furthermore, pouch-type LIBs with FSI-based electrolytes mounted on a demonstration module of a microsatellite were able to stably operate in space, ${ }^{11}$ demonstrating that pouch-type cells with FSI-based electrolytes can operate stably under severe conditions, such as vacuum and cosmic radiation environments.

In this study, we investigated the effects of lithium bis(fluorosulfonyl)imide (LiFSI) concentration in EMImFSI electrolytes on the performance of pouch-type LIBs. The IL electrolytes of LiFSI/ EMImFSI are composed of two cations, $\mathrm{Li}^{+}$and $\mathrm{EMIm}^{+}$, and one anion, $\mathrm{FSI}^{-}$. $\mathrm{Li}^{+}$and $\mathrm{FSI}^{-}$form complexes in the IL-based electrolytes and the viscosity and ionic conductivity increase and decrease, respectively, with increasing LiFSI concentration. The pouch-type cells of $\mathrm{LiNi}_{0.5} \mathrm{Mn}_{0.3} \mathrm{Co}_{0.2} \mathrm{O}_{2}$ (NMC532)/graphite were constructed using FSI-based IL electrolytes and battery tests were performed. We found that the $\mathrm{Li}^{+}$ion transport in the IL-based electrolyte was significantly influenced by the Li salt concentration and the rate capability of the NMC532/graphite cell can be improved by a high LiFSI concentration.

\section{Experimental}

EMImFSI and LiFSI were supplied by iElectrolyte Co., Ltd. EMImFSI and LiFSI were mixed to prepare the IL electrolytes. The ionic conductivity and viscosity of each electrolyte were measured by an external institution (Mitsui Chemical Analysis \& Consulting Service, Inc.). Pulsed-field gradient nuclear magnetic resonance 
(PFG-NMR) spectroscopy was used to evaluate the self-diffusion coefficient of $\mathrm{Li}^{+}\left({ }^{7} \mathrm{Li}\right)$ in the electrolyte on a JEOL ECX-400 NMR spectrometer with a $9.4 \mathrm{~T}$ narrow-bore superconducting magnet equipped with a pulsed-field gradient probe and current amplifier. Details of the PFG-NMR experimental procedure have been reported elsewhere. ${ }^{12}$ Chronoamperometry of $\mathrm{Li} / \mathrm{Li}$ symmetric cells was conducted with IL electrolytes at $25^{\circ} \mathrm{C}$. Two Li-metal foil electrodes $(16 \mathrm{~mm}$ diameter) and a glass-fiber separator (GA-55, $210 \mu \mathrm{m}$ thickness, Advantec) soaked with an IL electrolyte were encapsulated in a 2032-type coin cell. A constant DC voltage of ca. $5 \mathrm{mV}$ was applied to a coin cell and a chronoamperogram was recorded. AC impedance measurements for the coin cell were performed immediately before and after chronoamperometry. AC impedance measurements were conducted on the cell at an opencircuit voltage, with a $10 \mathrm{mV}$-rms amplitude in the frequency range of $1 \mathrm{MHz}$ to $0.1 \mathrm{~Hz}$, using an electrochemical instrument (VSP-300, Bio-Logic). The $\mathrm{Li}^{+}$transference number $\left(t_{\mathrm{Li}+}\right)$ of the electrolyte was calculated using the following equation: ${ }^{13}$

$$
t_{\mathrm{Li}+}=\frac{I_{\mathrm{ss}}\left(\Delta V-I_{\Omega} R_{\mathrm{i}, 0}\right)}{I_{\Omega}\left(\Delta V-I_{\mathrm{ss}} R_{\mathrm{i}, \mathrm{ss}}\right)}
$$

where $I_{\mathrm{SS}}$ is the steady-state current and $R_{\mathrm{i}, 0}$ and $R_{\mathrm{i}, \mathrm{SS}}$ are the interfacial resistance before and after polarization, respectively. $I_{\Omega}$ is the initial current calculated by Ohm's law: $I_{\Omega}=\Delta V /\left(R_{\mathrm{b}}+R_{\mathrm{i}, 0}\right)$, where $R_{\mathrm{b}}$ is the resistance of the bulk electrolyte.

A pouch cell with NMC532 and graphite electrodes, which were not filled with an electrolyte, were supplied by iElectrolyte Co., Ltd. A positive electrode - composed of NMC532 powder, a conductive agent, and an aqueous binder (96:2:2 in mass ratio) — was coated on Al foil. The mass loading of NMC532 on the Al foil was 13$14 \mathrm{mg} \mathrm{cm}^{-2}$. A negative electrode - composed of graphite powder, a conductive agent, and an aqueous binder (96:1:3 in mass ratio) - was coated on $\mathrm{Cu}$ foil. The mass loading of graphite on the $\mathrm{Cu}$ foil was $7.5-8.0 \mathrm{mg} \mathrm{cm}^{-2}$. Each single-side-coated positive and negative electrode was placed across a porous separator film $(25 \mu \mathrm{m}$ thick) in a pouch-type cell. The ratio of the negative/positive electrode capacity (N/P ratio) was approximately 1.1 . The areas of the positive and negative electrodes were $3 \times 6 \mathrm{~cm}^{2}$ and $3.2 \times 6.2$ $\mathrm{cm}^{2}$, respectively. The capacity of a pouch cell was approximately

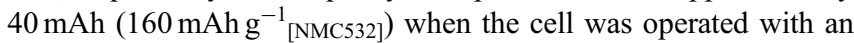
upper voltage limit of $4.2 \mathrm{~V}$. The pouch cells were dried for $10 \mathrm{~h}$ at $100^{\circ} \mathrm{C}$ under vacuum, before being filled with an electrolyte. The cells were sealed after the electrolyte was filled. The cell was charged to $4.2 \mathrm{~V}$, with a constant current of $0.1 \mathrm{C}$-rate $(1 \mathrm{C}$-rate $=$ $140 \mathrm{~mA} \mathrm{~g}^{-1}{ }_{\text {NMC532] }}$ ), and was maintained at a constant voltage until the current decreased to $0.01 \mathrm{C}$-rate; the cell was then discharged to $2.7 \mathrm{~V}$ at a constant current of $0.1 \mathrm{C}$-rate using a battery chargedischarge system (SD8, HOKUTO DENKO). After repeating this charge-discharge cycle twice, the cell was transferred to a glove box and opened for degassing. Subsequently, the cell was resealed and the battery performance was examined under various conditions.

\section{Results and Discussion}

Figure 1 shows the ionic conductivity $(\sigma)$ and viscosity $(\eta)$ of

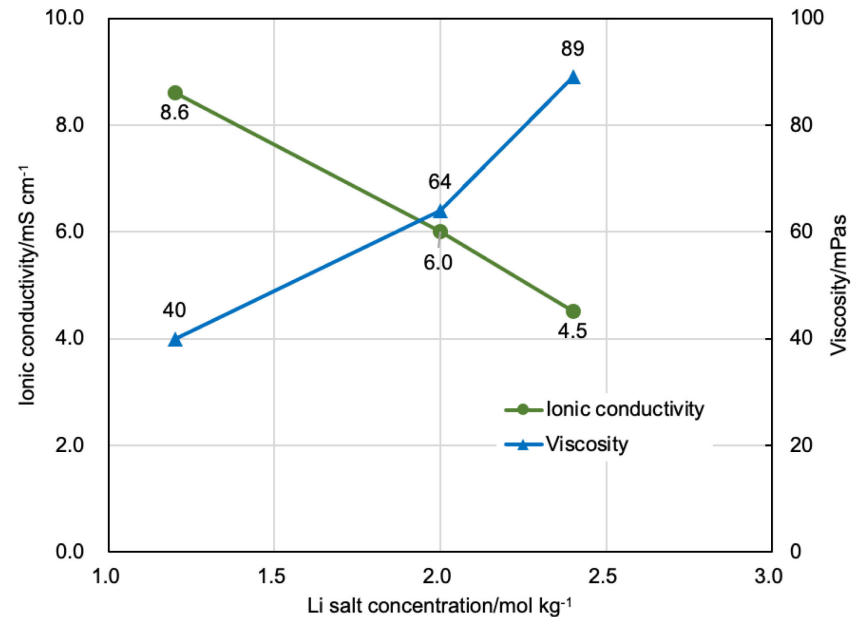

Figure 1. Ionic conductivity and viscosity of LiFSI/EMImFSI electrolytes at $25^{\circ} \mathrm{C}$.

the electrolytes. With increasing LiFSI concentration, the ionic conductivity decreases owing to the increased viscosity of the electrolyte. In the IL electrolytes, $\mathrm{Li}^{+}$ions form complexes with the FSI anion. According to Fujii et al., ${ }^{14}\left[\mathrm{Li}(\mathrm{FSI})_{3}\right]^{2-}$ is preferentially formed in FSI-based electrolytes that contain relatively low LiFSI concentrations $\left(<1 \mathrm{molkg}^{-1}\right)$. The molar ratios of $\mathrm{Li}^{+}: \mathrm{FSI}^{-}$in the electrolytes with high LiFSI concentrations of $2.0 \mathrm{~mol} \mathrm{~kg}^{-1}$ and $2.4 \mathrm{~mol} \mathrm{~kg}^{-1}$ are $1: 2.7$ and $1: 2.4$, respectively (Table 1 ). In these highly concentrated electrolytes, the amount of FSI anions is insufficient for all $\mathrm{Li}^{+}$ions to form $\left[\mathrm{Li}(\mathrm{FSI})_{3}\right]^{2-}$ complexes. Therefore, it is presumed that $\left[\mathrm{Li}(\mathrm{FSI})_{2}\right]^{-}$complexes are also formed in these electrolytes. ${ }^{15}$ The formation of complex structures, such as $\left[\mathrm{Li}(\mathrm{FSI})_{3}\right]^{2-}$ and $\left[\mathrm{Li}(\mathrm{FSI})_{2}\right]^{-}$, in the electrolytes caused an increase in the viscosity and a decrease in the mobility of $\mathrm{Li}^{+}$. The self-diffusion coefficient of $\mathrm{Li}^{+}$in the electrolyte decreased with increasing LiFSI concentration (Table 1). The $\mathrm{Li}^{+}$transfer numbers $\left(t_{\mathrm{Li}+}\right)$ in the electrolytes were estimated using $\mathrm{Li} / \mathrm{Li}$ symmetric cells under anion-blocking conditions (Fig. S1). As shown in Table 1, the values of $t_{\mathrm{Li}+}$ are relatively low $(<0.2)$, i.e., lower than those of conventional carbonate-based electrolytes. ${ }^{3}$ Ionic liquids consist entirely of ions and $\mathrm{EMI}^{+}$and $\mathrm{FSI}^{-}$ions are mobile in addition to $\mathrm{Li}^{+}$ions in the electrolytes. Furthermore, $\mathrm{Li}^{+}$ions form complexes with $\mathrm{FSI}^{-}$ions and the hydrodynamic radius of $\mathrm{Li}^{+}$becomes larger than those of $\mathrm{EMI}^{+}$and $\mathrm{FSI}^{-}$ions, resulting in the low mobility of $\mathrm{Li}^{+}$in the electrolytes. The value of $t_{\mathrm{Li}+}$ slightly increases with $\mathrm{Li}$ salt concentration and the values of the product of ionic conductivity $(\sigma)$ and $t_{\mathrm{Li}+}$ - i.e., $\sigma \times t_{\mathrm{Li}+}-$ of the three different electrolytes are similar. The product $\sigma \times t_{\mathrm{Li}+}$ is the effective $\mathrm{Li}^{+}$ion conductivity under anion-blocking conditions and the resistivity for $\mathrm{Li}^{+}$ion migration in the electrolyte of a Li-ion cell is $1 /\left(\sigma \times t_{\mathrm{Li}+}\right){ }^{16,17}$

We investigated the effects of electrolyte composition on the performance of the NMC532/graphite pouch cell. The pouch cells with three different electrolytes showed similar initial charge-

Table 1. Molar ratio of $\mathrm{Li}^{+}: \mathrm{EMI}^{+}: \mathrm{FSI}^{-}$, viscosity $(\eta)$, ionic conductivity $(\sigma)$, self-diffusion coefficient of $\mathrm{Li}^{+}\left(D_{\mathrm{Li}+}\right), \mathrm{Li}^{+}$transfer number $\left(t_{\mathrm{Li}+}\right)$, and $\sigma \times t_{\mathrm{Li}+}$ of IL electrolytes at $25^{\circ} \mathrm{C}$.

\begin{tabular}{|c|c|c|c|c|c|c|c|c|}
\hline \multirow{2}{*}{$\begin{array}{c}\text { Molality } \\
{\left[\mathrm{mol} \mathrm{kg}^{-1}\right]}\end{array}$} & \multicolumn{3}{|c|}{ Molar ratio } & \multirow{2}{*}{$\begin{array}{c}\eta \\
{[\mathrm{mPa} \mathrm{s}]}\end{array}$} & \multirow{2}{*}{$\begin{array}{c}\sigma \\
{\left[\mathrm{mS} \mathrm{cm}^{-1}\right]}\end{array}$} & \multirow{2}{*}{$\begin{array}{c}D_{\mathrm{Li}+} \times 10^{-7} \\
{\left[\mathrm{~cm}^{2} \mathrm{~s}^{-1}\right]}\end{array}$} & \multirow{2}{*}{$\begin{array}{l}t_{\mathrm{Li}+} \\
{[-]}\end{array}$} & \multirow{2}{*}{$\begin{array}{c}\sigma \times t_{\mathrm{Li}+} \\
{\left[\mathrm{mS} \mathrm{cm}^{-1}\right]}\end{array}$} \\
\hline & $\mathrm{Li}^{+}$ & $\mathrm{EMI}^{+}$ & $\mathrm{FSI}^{-}$ & & & & & \\
\hline 1.2 & 1 & 2.9 & 3.9 & 40 & 8.4 & 2.65 & $0.08 \pm 0.01$ & $0.67 \pm 0.08$ \\
\hline 2.0 & 1 & 1.7 & 2.7 & 64 & 6.0 & 1.73 & $0.12 \pm 0.01$ & $0.72 \pm 0.06$ \\
\hline 2.4 & 1 & 1.4 & 2.4 & 89 & 4.5 & 1.38 & $0.15 \pm 0.02$ & $0.67 \pm 0.09$ \\
\hline
\end{tabular}


discharge behaviors at $0.1 \mathrm{C}$-rate (Fig. S2). Reversible discharge capacities of NMC532/graphite cells with electrolytes of 1.2 mol kg ${ }^{-1}, 2.0 \mathrm{~mol} \mathrm{~kg}^{-1}$, and $2.4 \mathrm{~mol} \mathrm{~kg}^{-1} \mathrm{LiFSI} / \mathrm{EMImFSI}$ are $165 \mathrm{mAh} \mathrm{g}^{-1}, 166 \mathrm{mAhg}^{-1}$, and $163 \mathrm{mAhg}^{-1}$, respectively, at the 2nd cycle. Figure 2 shows the discharge curves of the cells measured at various currents at $25^{\circ} \mathrm{C}$. At currents lower than $1 \mathrm{C}$ rate, the three cells showed similar discharge curves. With increasing current, the discharge voltage of each cell decreases due to the IR drop in the electrolyte and the overvoltage for electrochemical reactions at the cathode and anode. At currents higher than $2 \mathrm{C}$-rate, the sloping of the discharge curve becomes steeper and the cell voltage reaches the cut-off voltage $(2.7 \mathrm{~V})$ before achieving the full capacity $\left(\sim 160 \mathrm{mAh} \mathrm{g}^{-1}\right)$ of the cell. The discharge capacities at $2 \mathrm{C}$-rate and $5 \mathrm{C}$-rate increased with increasing LiFSI concentration. The steeper slope of the discharge curves observed at high currents in Fig. 2 indicates that the mass transport process (i.e., the diffusion of $\mathrm{Li}^{+}$ions) in the electrolyte controls the discharge reaction in the cell. During discharging, $\mathrm{Li}^{+}$ ions are released from the graphite anode and consumed by the NMC532 cathode. At high currents, the LiFSI concentration increases in the vicinity of the graphite electrode and decreases in the vicinity of the NMC532 cathode and a concentration gradient of LiFSI might develop in the electrolyte. The discharge voltage should drop rapidly when the depletion of LiFSI occurs in the vicinity of NMC532. The high concentration of LiFSI might be favorable for mitigating the depletion of $\mathrm{Li}^{+}$at the cathode surface. The transport processes of $\mathrm{Li}^{+}$in the electrolyte are migration and diffusion. As can be seen in Table 1, the values of effective $\mathrm{Li}^{+}$ion conductivity, $\sigma \times t_{\mathrm{Li}+}$, of the three different electrolytes are similar; therefore, the resistivity for $\mathrm{Li}^{+}$ion migration in the Li-ion cells with these electrolytes might be similar (vide supra). When the discharge current was relatively low, the current was mainly controlled by the migration of $\mathrm{Li}^{+}$ions, resulting in similar discharge curves at a low current ( $\sim 0.1 \mathrm{C}$-rate). However, at higher discharge currents, a steeper concentration gradient might form between the anode and cathode and $\mathrm{Li}^{+}$transport is presumed to be controlled by the diffusion process.

To further investigate the $\mathrm{Li}^{+}$transport in the electrolyte, a voltage step was applied to the cell and chronoamperometry was conducted. A voltage step of $\Delta V=-0.8 \mathrm{~V}$ was applied to the cell of state-of-charge (SOC) $100 \%$. The open-circuit voltage of the cell at SOC $100 \%$ was in the range $4.20-4.19 \mathrm{~V}$, and the cell voltage was changed to $3.4 \mathrm{~V}$ through the voltage step. Chronoamperograms of cells with different electrolytes are shown in Fig. 3. Immediately after the voltage step, a large current was observed for each cell and the current decayed rapidly over time. The charge transfer reactions at the electrode/electrolyte interfaces are accelerated by the applied large overvoltage. The particles of cathode and anode active materials are known to exhibit rather high-rate discharge capabilities. For example, a cathode particle having a layered crystal structure can discharge at $80 \mathrm{C}$-rate, ${ }^{18}$ and a graphite particle can discharge at $100 \mathrm{C}$-rate. ${ }^{19}$ Therefore, the current observed during the voltage step was presumed to be controlled mainly by the $\mathrm{Li}^{+}$ion transport in the electrolyte. Both $\mathrm{Li}^{+}$migration and $\mathrm{Li}^{+}$diffusion were accelerated under a large overvoltage. The potential slope formed in the electrolyte/separator should be steep immediately after polarization. In addition, the concentration gradients near the electrodes are steep because the diffusion layers immediately after the polarization are very thin. The concentration polarization is prone to occur in the electrolyte with low $t_{\mathrm{Li}+} \cdot{ }^{20}$ The values of $t_{\mathrm{Li}+}$ of the IL electrolytes are rather low $(<0.15)$, as presented in Table 1 . Therefore, the current immediately after the polarization is presumed to be controlled mainly by $\mathrm{Li}^{+}$diffusion in the electrolyte. After the voltage step, the concentration gradient of LiFSI is formed at the vicinities of the anode and cathode owing to the $\mathrm{Li}^{+}$release from the anode and the consumption at the cathode, respectively, and the
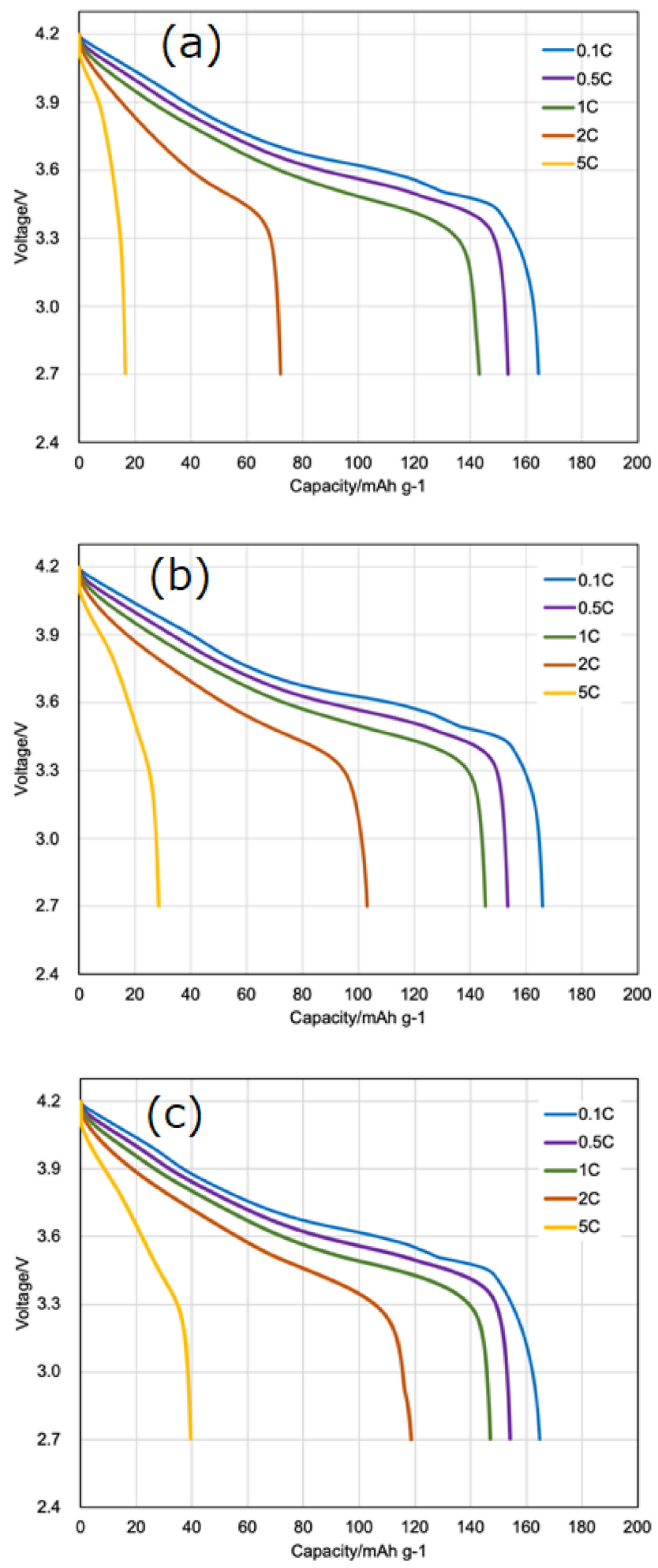

Figure 2. Discharge curves of NMC532/graphite pouch cells with (a) $1.2 \mathrm{~mol} \mathrm{~kg}^{-1}$, (b) $2.0 \mathrm{~mol} \mathrm{~kg}^{-1}$, and (c) $2.4 \mathrm{~mol} \mathrm{~kg}^{-1} \mathrm{LiFSI} /$ EMImFSI. Prior to each discharge, the cells were charged to $4.2 \mathrm{~V}$ at a current of $0.2 \mathrm{C}$-rate and the cell voltage was maintained at $4.2 \mathrm{~V}$ until the current decreased to $0.02 \mathrm{C}$-rate.

diffusion layers grow over time. The current decay was due to the growth of the diffusion layer in the electrolyte. As the diffusion layer grows, the concentration gradient becomes gentle, resulting in the decay of the diffusion-controlled current. When the diffusion layers of the anode and cathode overlap in the separator, the growth of diffusion layers are almost complete and the current then changes 

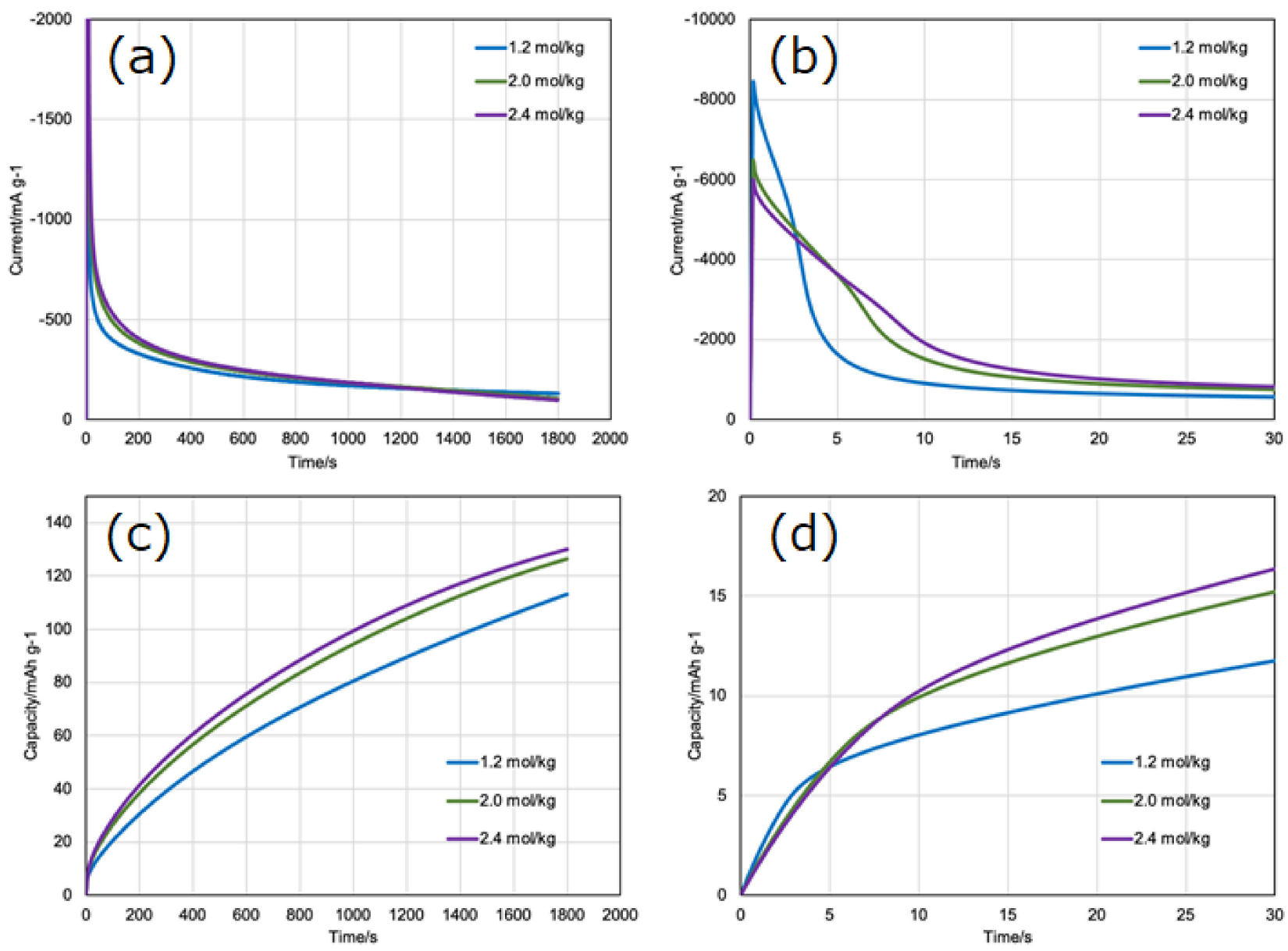

Figure 3. Chronoamperograms of NMC532/graphite pouch cells measured with voltage step from SOC $100 \%$ ( $4.2 \mathrm{~V}$ ) to $3.4 \mathrm{~V}$ in the period (a) $0-1800 \mathrm{~s}$ and (b) $0-30 \mathrm{~s}$. Cumulative discharge capacities of the cells during the chronoamperometry in the period (c) $0-1800 \mathrm{~s}$ and (d) $0-30 \mathrm{~s}$.

slightly, approaching steady-state. As shown in Fig. 3, the current decayed rapidly in the initial $\sim 10 \mathrm{~s}$ after the voltage step and then gradually decreased, indicating that the growth of diffusion layer in the separator almost completed within $10 \mathrm{~s}$. The thickness of the diffusion layer after the voltage step can be roughly described as $(\pi D t)^{1 / 2}$ where $D$ is the diffusion coefficient of $\mathrm{Li}^{+}$and $t$ is time. ${ }^{21}$ The diffusion coefficient of $\mathrm{Li}^{+}$in the electrolyte is in the order of $10^{-7} \mathrm{~cm}^{2} \mathrm{~s}^{-1}$ (Table 1), and the thickness of the diffusion layer of each electrode in the cell can be roughly estimated to be $20 \mu \mathrm{m}$ at $10 \mathrm{~s}$. The thickness of the separator is $25 \mu \mathrm{m}$; therefore, we can reasonably assume that the diffusion layers of the anode and cathode overlap within $10 \mathrm{~s}$.

As can be seen in Fig. 3, the cell with $1.2 \mathrm{~mol} \mathrm{~kg}^{-1} \mathrm{LiFSI}$ electrolyte showed the largest current at the early stage of polarization within $3 \mathrm{~s}$; this is because the diffusion coefficient of $\mathrm{Li}^{+}$in the $1.2 \mathrm{~mol} \mathrm{~kg}^{-1} \mathrm{LiFSI}$ electrolyte is higher than that in the other two electrolytes (Table 1). With increasing LiFSI concentration, the viscosity of the electrolyte increased and the diffusion coefficient of $\mathrm{Li}^{+}$decreased. According to Fick's first law, the diffusion-controlled current, $I$, can be described as $I=-F A D(\partial c /$ $\partial x$ ), where $F$ is the Faraday constant, $A$ is the geometric surface area of the electrode, and $\partial c / \partial x$ is the concentration gradient. Immediately after the voltage step, the thickness of the diffusion layer was very thin and the concentration gradient was very steep in each cell. Therefore, the higher diffusion coefficient of $\mathrm{Li}^{+}$might result in a higher initial current. After $3 \mathrm{~s}$, the currents of the cells with $2 \mathrm{~mol} \mathrm{~kg}^{-1}$ and $2.4 \mathrm{~mol} \mathrm{~kg}^{-1} \mathrm{LiFSI}$ electrolytes become higher than that of the cell with $1.2 \mathrm{~mol} \mathrm{~kg}^{-1}$ LiFSI electrolyte, suggesting that the flux of $\mathrm{Li}^{+}$across the separator is greater in the electrolytes with higher LiFSI concentration. The higher diffusion coefficient of $\mathrm{Li}^{+}$in the $1.2 \mathrm{~mol} \mathrm{~kg}^{-1} \mathrm{LiFSI}$ leads to faster growth of the diffusion layer, ${ }^{21}$ resulting in a more rapid decay of the current. Conversely, the lower diffusion coefficients in the $2 \mathrm{~mol} \mathrm{~kg}^{-1}$ and $2.4 \mathrm{~mol} \mathrm{~kg}^{-1}$ LiFSI electrolytes resulted in slower growth of the diffusion layer and the current decayed gently. After the diffusion layer develops in the separator, the concentration gradient can be roughly approximated as $\Delta c / l$, where $\Delta c$ is the difference in LiFSI concentration between the cathode and anode and $l$ is the thickness of the separator. The value of $\Delta c$ can be greater for electrolytes with higher LiFSI concentrations. When the LiFSI concentration at the cathode side becomes zero, the LiFSI concentration at the anode side should be $2 c_{\mathrm{Li}+}\left(c_{\mathrm{Li}+}\right.$ : molar concentration $\left(\mathrm{mol} \mathrm{dm}^{-3}\right)$ of $\mathrm{Li}^{+}$in the initial electrolyte), considering the mass balance in the electrolyte. Therefore, $\Delta c$ increases in the electrolyte with a higher LiFSI concentration. Although the diffusion coefficient of $\mathrm{Li}^{+}$is lower in the electrolyte with higher LiFSI concentration, the product of the diffusion coefficient and concentration gradient, $D \times \Delta c / l$, might be higher for the electrolyte with higher LiFSI concentration, resulting in a higher diffusion-controlled current after $3 \mathrm{~s}$. In addition, the high concentration of LiFSI is effective in suppressing the depletion of $\mathrm{Li}^{+}$in the vicinity of cathode (vide supra). This is effective in facilitating the discharge reaction of NMC532 particles existing close to the $\mathrm{Al}$ current collector in the porous cathode, and this may also contribute to the larger current in the electrolyte with higher LiFSI concentration. The cumulative discharge capacities of the cells during chronoamperometry are shown in Fig. 3. Owing to the 

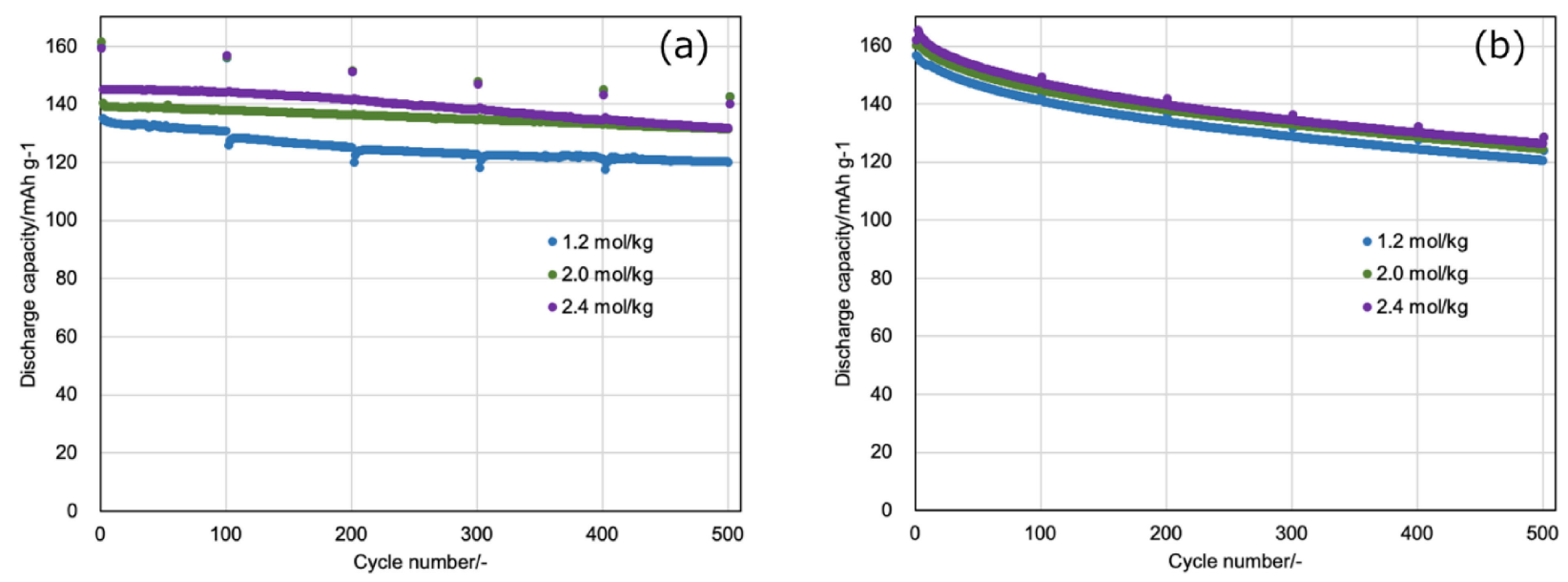

Figure 4. Charge-discharge cycle stability of NMC532/graphite pouch cells with $1.2 \mathrm{~mol} \mathrm{~kg}^{-1}, 2.0 \mathrm{~mol} \mathrm{~kg}^{-1}$, and $2.4 \mathrm{~mol} \mathrm{~kg}-1$ LiFSI/ EMImFSI at (a) $25^{\circ} \mathrm{C}$ and (b) $60^{\circ} \mathrm{C}$. The cells were charged to $4.2 \mathrm{~V}$ at a current of $1 \mathrm{C}$-rate and the cell voltage was maintained at $4.2 \mathrm{~V}$ until the current decreased to $0.1 \mathrm{C}$-rate; the cells were then discharged to $2.7 \mathrm{~V}$ at $1 \mathrm{C}$-rate. The capacity retention of the cells was checked at $0.1 \mathrm{C}$ rate every 100 cycles.

higher current after $3 \mathrm{~s}$ in the cells with higher LiFSI concentrations, higher cumulative discharge capacities can be achieved. The results of chronoamperometry were consistent with the rate capabilities of the cells assessed by galvanostatic measurements (Fig. 2). Consequently, the higher LiFSI concentration in the FSI-based IL electrolyte is advantageous for achieving a high rate capability of a Li-ion cell.

Finally, we investigated the charge-discharge cycle performance of NMC532/graphite cells. The charge-discharge cycle test was conducted at $1 \mathrm{C}$-rate and the capacity retention of the cell was checked at $0.1 \mathrm{C}$-rate every 100 cycles. Figure 4 shows the discharge capacities of the cells. Each cell can be operated stably over 500 cycles at $25^{\circ} \mathrm{C}$ and $60^{\circ} \mathrm{C}$. We note here that the cells can also be operated at $-20^{\circ} \mathrm{C}$ if the charge-discharge current is relatively low ( $\sim 0.1 \mathrm{C}$-rate) (Fig. S3). Thus, Li-ion cells with LiFSI/EMIFSI electrolytes can be operated over a wide temperature range. As can be seen in Fig. 4, the cell with $2.4 \mathrm{~mol} \mathrm{~kg}^{-1} \mathrm{LiFSI}$ electrolyte delivered higher capacity compared to ones with $1.2 \mathrm{~mol} \mathrm{~kg}^{-1}$ and $2.0 \mathrm{~mol} \mathrm{~kg}^{-1}$ LiFSI electrolytes at $1 \mathrm{C}$-rate. However, the discharge capacity of the cells measured at a low current of $0.1 \mathrm{C}$-rate was almost independent of the electrolyte composition. The discharge capacity of each cell gradually decreased with the cycle number. The discharge capacity retention of the cells with $1.2 \mathrm{~mol} \mathrm{~kg}^{-1}, 2.0 \mathrm{~mol} \mathrm{~kg}^{-1}$, and $2.4 \mathrm{~mol} \mathrm{~kg}^{-1} \mathrm{LiFSI}$ electrolytes at the 500th cycle were $89.1 \%, 88.3 \%$, and $88.1 \%$, respectively, at $25^{\circ} \mathrm{C}$, and $79.1 \%, 80.2 \%$, and $79.4 \%$, respectively, at $60^{\circ} \mathrm{C}$. The LiFSI concentration did not significantly affect the capacity retention. The capacity decay was slightly faster at $60^{\circ} \mathrm{C}$, indicating that the subtle irreversible process, such as the fracture of SEI and the decomposition of the electrolyte, during chargedischarge was accelerated at elevated temperatures.

\section{Conclusions}

The IL electrolytes of LiFSI/EMImFSI with different LiFSI concentrations were tested in NMC532/graphite pouch cells. The ionic conductivity of the electrolyte decreased with increasing LiFSI concentration due to the increase in viscosity; however, the $\mathrm{Li}^{+}$ transference number increased with increasing LiFSI concentration, resulting in the effective $\mathrm{Li}^{+}$ion conductivity, $\sigma \times t_{\mathrm{Li}+}$, becoming more or less independent of LiFSI concentration in $1.2-2.4 \mathrm{~mol} \mathrm{~kg}^{-1}$ LiFSI/EMImFSI electrolytes. The discharge rate capability of an NMC532/graphite pouch cell with a higher LiFSI concentration electrolyte was better than that of the cell with a lower LiFSI concentration, regardless of the similar values of $\sigma \times t_{\mathrm{Li}+}$ of these electrolytes; this suggests that the current during the high-rate discharging was mainly controlled by $\mathrm{Li}^{+}$ion diffusion rather than $\mathrm{Li}^{+}$migration in the electrolyte. Using a high-concentration LiFSI electrolyte, the depletion of $\mathrm{Li}^{+}$in the vicinity of the NMC532 cathode during the high current discharge can be suppressed, leading to an improved rate capability of the cell. A steeper concentration gradient of LiFSI can be formed in the electrolyte/separator using a higher LiFSI concentration electrolyte, resulting in greater $\mathrm{Li}^{+}$flux in the electrolyte. The charge-discharge cycle stability of the pouch cell was independent of the LiFSI concentration and the cell could be operated for 500 cycles with capacity retentions of $88 \%$ and $80 \%$ at $25^{\circ} \mathrm{C}$ and $60^{\circ} \mathrm{C}$, respectively. This study demonstrates that IL electrolytes with higher LiFSI concentrations can improve the rate capability of LIBs and further optimization of the electrolyte formulation may be needed to improve the performance of LIBs and expand the application of LIBs with IL electrolytes.

\section{Data Availability Statement}

Nyquist plots before and after polarization, and chronoamperograms for $\mathrm{Li} / \mathrm{Li}$ cells, the initial two charge-discharge curves of NMC532/graphite pouch cells, and the discharge curves of NMC532/graphite pouch cells measured at $-20^{\circ} \mathrm{C}$. The data that support the findings of this study are openly available under the terms of the designated Creative Commons License in J-STAGE Data at https://doi.org/10.50892/data.electrochemistry.14992347.

\section{Conflicts of interest}

There are no conflicts of interest to declare.

\section{References}

1. K. J. Nelson, J. Xia, and J. R. Dahn, J. Electrochem. Soc., 161, A1884 (2014).

2. R. Petibon, E. C. Henry, J. C. Burns, N. N. Sinha, and J. R. Dahn, J. Electrochem. Soc., 161, A66 (2014).

3. A. S. Keefe, R. Weber, I. G. Hill, and J. R. Dahn, J. Electrochem. Soc., 167, 120507 (2020)

4. Y. Yamada, M. Yaegashi, T. Abe, and A. Yamada, Chem. Commun., 49, 11194 (2013).

5. Y. Yamada, Y. Takazawa, K. Miyazaki, and T. Abe, J. Phys. Chem. C, 114, 11680 (2010). 
6. M. Watanabe, M. L. Thomas, S. Zhang, K. Ueno, T. Yasuda, and K. Dokko, Chem. Rev. 117, 7190 (2017)

7. M. Ishikawa, T. Sugimoto, M. Kikuta, E. Ishiko, and M. Kono, J. Power Sources, 162, 658 (2006).

8. Y. Matsui, S. Kawaguchi, T. Sugimoto, M. Kikuta, T. Higashizaki, M. Kono, M. Yamagata, and M. Ishikawa, Electrochemistry, 80, 808 (2012).

9. T. Sugimoto, Y. Atsumi, M. Kono, M. Kikuta, E. Ishiko, M. Yamagata, and M. Ishikawa, J. Power Sources, 195, 6153 (2010).

10. T. Takahashi, M. Yamagata, and M. Ishikawa, Prog. Nat. Sci., 25, 612 (2015).

11. M. Yamagata, K. Tanaka, Y. Tsuruda, Y. Sone, S. Fukuda, S. Nakasuka, M. Kono, and M. Ishikawa, Electrochemistry, 83, 918 (2015).

12. Y. Ugata, M. L. Thomas, T. Mandai, K. Ueno, K. Dokko, and M. Watanabe, Phys. Chem. Chem. Phys., 21, 9759 (2019).

13. M. D. Galluzzo, J. A. Maslyn, D. B. Shah, and N. P. Balsara, J. Chem. Phys., 151, 020901 (2019).
14. K. Fujii, H. Hamano, H. Doi, X. Song, S. Tsuzuki, K. Hayamizu, S. Seki, Y. Kameda, K. Dokko, M. Watanabe, and Y. Umebayashi, J. Phys. Chem. C, 117(38), 19314 (2013).

15. H. Yoon, A. S. Best, M. Forsyth, D. R. MacFarlane, and P. C. Howlett, Phys. Chem. Chem. Phys., 17, 4656 (2015).

16. F. Sälzer, L. P. Pescara, F. Franke, C. Müller, J. Winkler, M. Schwalm, and B. Roling, Batteries Supercaps, 3, 117 (2020).

17. N. M. Vargas-Barbosa and B. Roling, ChemElectroChem, 7, 367 (2020).

18. K. Yoshida, M. Tsuchiya, N. Tachikawa, K. Dokko, and M. Watanabe, J. Electrochem. Soc., 159, A1005 (2012).

19. K. Dokko, N. Nakata, Y. Suzuki, and K. Kanamura, J. Phys. Chem. C, 114, 8646 (2010).

20. M. Doyle, T. F. Fuller, and J. Newman, Electrochim. Acta, 39, 2073 (1994).

21. J. Bard and L. R. Faulkner, Electrochemical Methods, Fundamentals and Applications, John Wiley \& Sons, New York, NY (1980). 